\title{
reCHERches
}

Culture et histoire dans l'espace roman

$25 \mid 2020$

Mentir au théâtre

\section{Hopper's Blue Night (Sobre la mentira)}

\section{Miguel Palacios}

\section{(2) OpenEdition}

\section{Journals}

\section{Edición electrónica}

URL: https://journals.openedition.org/cher/406

DOI: $10.4000 /$ cher.406

ISSN: 2803-5992

\section{Editor}

Presses universitaires de Strasbourg

\section{Edición impresa}

Fecha de publicación: 19 noviembre 2020

Paginación: 172-188

ISBN: 979-10-344-0071-3

ISSN: 1968-035X

\section{Referencia electrónica}

Miguel Palacios, «Hopper's Blue Night (Sobre la mentira)», reCHERches [En línea], 25 | 2020, Publicado el 01 octubre 2021, consultado el 20 noviembre 2021. URL: http://journals.openedition.org/cher/406 ; DOI: https://doi.org/10.4000/cher.406 


\title{
Hopper's Blue Night \\ (Sobre la mentira)
}

\author{
Version espagnole
}

Los personajes y hechos retratados en esta obra son completamente ficticios. Cualquier parecido con personas verdaderas, vivas o muertas, o con hechos reales es mera coincidencia.

Francis B.

Miguel Palacios

MaLENA

La Madre de Francis

En Málaga, hacia 2014.

\section{Lane Road, 19541}

Mi abuelo es la persona que más ha influido en mi vida. Era un gran tipo. El 18 de julio le pilló en Churriana, donde vivía su familia. En febrero del 1937, con sus padres y hermanos participó en la "Desbandá", la huida de la población malagueña hacia Almería por la carretera de la playa ante la inminente llegada del ejército fascista del general Franco. Tenía trece años y nunca se había interesado por la política, pero la masacre de la que fue testigo hizo que comenzase a hacerlo. ¿Qué ideología justifica que se bombardee a la población civil por tierra, mar y aire?

Un mes más tarde, en marzo del treinta y siete, ya estaba pegando tiros en Madrid contra el ejército golpista. También luchó en la Sierra de Pàndols y en Barcelona. En abril de 1939, consciente de que la República había sido derrotada, cruzó la frontera francesa y, en agosto de ese mismo año, se embarcó en el Winnipeg rumbo a Valparaíso.

No volvió a España hasta la muerte del dictador. Entonces se instaló en Torremolinos, desde donde continuó trabajando para el pueblo como activista, concejal del Ayuntamiento de Benalmádena y diputado del PSOE en el recién inaugurado parlamento andaluz.

Era un tipo íntegro, serio, que no se andaba con chiquitas, pero honesto y justo a más no poder. A mí siempre me trató bien: “el jefecito”, me llamaba, porque, decía, era el que tenía más carácter de todos sus nietos. En la época en que las cosas con mis padres comenzaron a torcerse, él y mi abuela fueron los únicos que me tendieron la mano.

Lo echo de menos, sí. También a ella. No hay un día que pase en el que no lo recuerde, por eso digo que es la persona de mi familia que más ha influido en mi vida; en todo lo que hago trato de parecerme a él.

1 Los títulos de las 21 escenas recogen los títulos de 21 obras d'Edward Hopper y las fechas de las mismas. 


\section{Hopper's Blue Night \\ (Au sujet du mensonge)}

\section{Version française ${ }^{1}$}

Les personnages et les faits mis en scène dans cette œuvre sont totalement fictifs. Toute ressemblance avec des personnes ayant existé ou des faits réels serait purement fortuite.

Francis B.

Miguel

Malena

LA MÈRE DE FRANCIS

Malaga, vers 2014.

\section{Lane Road, $1954^{2}$}

Mon grand-père est la personne qui a le plus influencé ma vie. C'était vraiment quelqu'un. Le 18 juillet le surprit à Churriana, où il vivait avec sa famille. En février 1937, il participa avec ses parents et ses frères et sœurs à la «Desbandá », cet exode de la population de Malaga vers Alméria, par la route de la côte, face à l'imminence de l'arrivée de l'armée fasciste du général Franco. Il avait treize ans et n'avait jamais été intéressé par la politique, mais le massacre dont il fut témoin commença à changer la donne. Quelle idéologie peut justifier de bombarder la population civile depuis la terre, le ciel et la mer?

À peine un mois plus tard, en mars 1937, il se trouvait à Madrid à faire feu sur l'armée du coup d'état. Il la combattit aussi dans la Sierra de Pàndols, et à Barcelone. En avril 1939, conscient de la défaite des Républicains, il traversa la frontière française et, en août de cette même année, il embarqua sur le Winnipeg, direction Valparaiso.

Il ne revint en Espagne qu'à la mort du dictateur. Il s'établit alors à Benalmádena, où il continua à œuvrer pour le peuple comme activiste, conseiller municipal et député socialiste au tout récent parlement andalou.

C'était un homme intègre, droit, qui ne s'embarrassait pas de fioritures, le plus honnête et le plus juste des hommes. Il a toujours été gentil avec moi: il m'appelait son "petit chef», parce que, disait-il, c'est moi qui avais le plus de tempérament de tous ses petits-enfants. À l'époque où les choses commencèrent à se compliquer avec mes parents, il n'y eut que lui et ma grand-mère pour me tendre la main.

Il me manque, ça oui. Et elle aussi. Il ne se passe pas un jour sans que je pense à lui, c'est pour cela que je dis que c'est la personne qui a le plus influencé ma vie; j'essaie de lui ressembler en tout.

1 Traduction de Stéphane Oury.

2 Les titres des 21 scènes reprennent les titres de 21 tableaux d'Edward Hopper ainsi que leurs dates. 


\section{Office at Night, 1940}

Perdona, tío, estaba en una entrevista de trabajo; no he podido ni llamarte. Necesito pasta, ya lo sabes. Es para subdirector de comunicación de un partido político. Mejor ni te digo cuál, ;fliparías! Van de liberales, pero el facherío se huele de lejos. Estos ni son liberales, ni de la derechona, estos son fachas con denominación de origen, fachas de los de cuadro de Franco en el despacho, "una grande y libre" y "el fin justifica los medios". ¡Vaya panda de angelitos!

Me pasó el contacto Quino, el de la empresa de cáterin, lo conoces... ¡Hombre!, ponerme corbata, pase, pero lo de cantar "El novio de la muerte”, es que ni aunque quisiera; no me la sé.

No te mosquees conmigo. Me hace falta el dinero, es la única forma de seguir buscando inversores. Si me contratan, los mino desde dentro.

Ya verás, de aquí a nada estamos rodando tu guión.

\section{Nighthawks, 1942}

Ya, hemos intercambiado algunos mensajes. Me ha dicho lo del dinero y también lo de esa estúpida entrevista. No sé por qué hace esas cosas. Se le está yendo la pelota $(\ldots)^{2}$ Por eso te digo. Os va a salir por cuatro perras y te aseguro que va a funcionar. Es divertida, comprometida, honesta y lo que cuenta está a la orden del día; la distribución la tenéis fácil. Además, podéis apañaros los dos solos: tú en escena y Francis en la dirección y como técnico. (...) No te preocupes por eso, yo te ayudo con la interpretación..., y a él también, ¡claro! Me llamáis y ya está. (...) Nada. Los derechos, solo eso. Lo hago por arrimar el hombro ¿Cómo lo ves?

\section{A Woman in the Sun, 1961}

Gaby..., en fin, no debería decírtelo, pero ella... La última vez que la vi nos escapamos de clase y nos vinimos a comer al Palo. Nos pusimos ciegos de espetos y estuvimos privando hasta que se hizo de noche. Estaba tan borracha que se meó encima. ¿Puedes creerlo? Se meó encima, tío. ¡Me dio una pena!

No tengo noticias suyas desde hace meses. Sé que está bien por amigos comunes, pero no me coge el teléfono. Eso es buena señal, seguramente andará en Proyecto Hombre; lo digo porque les doy una mano como voluntario desde hace años y me consta que, para evitar tentaciones, cuando empiezan el programa tienen prohibido relacionarse con los compinches de desfase.

Lo que te voy a contar es una cabronada, en fin...: Gaby estaba sin trabajo, pero mantenía su piso en Mijas Costa y nunca le faltaban ni su gramito de farlopa, ni sus trescientos euritos que quemar. Guapa, elegante, sexy y con

2 (...) para indicar a lo largo de la obra lo que dice el interlocutor fuera de campo (por teléfono, videoconferencia...), pero que no oye el espectador. 


\section{Office at Night, 1940}

Excuse-moi, vieux, j'étais en plein entretien d'embauche; je n'ai même pas pu t'appeler. J'ai besoin de blé, tu sais. C'est pour un poste de sous-directeur de la communication pour un parti politique. Je préfère ne pas te dire lequel, tu hallucinerais. Ils se la jouent libéraux, mais ça sent le facho à plein nez. Ce ne sont pas des libéraux, ni la bonne vieille droite des familles, non, ce sont des fascistes dans la règle de l'art, de gros fachos du genre à avoir le portrait de Franco sur leur bureau, «Une, Grande et Libre» et «la fin justifie les moyens». De vrais petits anges!

C'est Quino, le type du traiteur, qui m'a refilé le contact, tu le connais. Écoute, vieux, mettre une cravate, passe encore, mais chanter «El novio de la muerte $»^{3} . .$. , franchement, même si je voulais, je ne connais pas les paroles.

$\mathrm{Ne}$ te fâche pas. J'ai besoin d'argent, et c'est la seule manière de continuer à chercher des investisseurs. Si je suis pris, je vais les miner de l'intérieur. Tu vas voir! Et, en un rien de temps, on se met à tourner ton scénar'.

\section{Nighthawks, 1942}

Je vois, on a échangé quelques messages. Il m'a dit pour l'argent; et aussi pour ce stupide entretien d'embauche. Il ne tourne pas rond, ces derniers temps $(\ldots)^{4}$. C'est pour ça, ça va vous coûter trois fois rien et je te promets que ça va marcher. C'est amusant, engagé, honnête, et ce que ça raconte est dans l'air du temps, et la distribution, ça n'est pas un problème pour vous. En plus, vous pouvez tout faire à tous les deux: toi sur scène, et Francis pour la direction et la partie technique (...) Ne t'en fais pas, je t'aiderai pour l'interprétation, et lui aussi, bien sûr! Vous m'appelez et c'est bon. (...) Non, rien. Juste les droits. Je fais ça, histoire qu'on se serre les coudes. Qu'est-ce que t'en dis?

\section{A woman in the Sun, 1961}

Gaby..., bref, je ne devrais pas te le dire, mais elle... La dernière fois que je l'ai vue, on a séché les cours et on est venu manger dans le quartier du Palo. On s'est empiffré de sardines grillées et on a picolé jusqu'à la tombée de la nuit. Elle était tellement bourrée qu'elle s'est pissée dessus. Tu peux le croire? Elle s'est pissée dessus, man! Elle m’a fait pitié!

Je n'ai pas eu de ses nouvelles depuis des mois. Je sais qu'elle va bien, par des amis communs, mais elle ne répond pas au téléphone. Ça, c’est bon signe, elle doit sûrement être chez SOS Addictions; je dis ça parce que je leur file un coup de main comme bénévole depuis des années et je crois savoir que pour éviter toute tentation, lorsque quelqu'un s'engage dans le programme, il lui est interdit d'avoir des contacts avec ses potes de débauche.

3 Hymne de la Légion, récupéré, actuellement, par le parti d'extrême droite, vox..

4 (...) pour indiquer, tout au long de la pièce, ce que dit l'interlocuteur hors-champ (au téléphone, par visioconférence...) et que n'entendent pas les spectateurs. 
dos móviles, el personal y el de un curro que, en teoría, no tenía. Blanco y en botella...

Que quede claro, no la estoy juzgando; para sobrevivir, cada uno vende lo que tiene.

\section{Hotel Window, 1955}

Perdona que te llame, es que estoy muy preocupada por Francis. (...) Su padre biológico murió hace un par de semanas. De verdad, perdóname, pero, por favor, trata de comprenderme, soy su madre, no puedo dejar de preocuparme por él. Su padre era un fiestero de Torremolinos; se pasó la vida rodeado de vagos, putas y drogadictos como él; y así acabó, muerto como un perro entre dos contenedores. Me da miedo que Francis termine igual. Con cerca de cuarenta años y ha dejado el trabajo. Estaba bien, la tele le gusta, es buen cámara. ¿Qué vida le espera? (...) Que va a pasar como con Canal Nou, sí, a mí también me lo ha dicho, pero no es excusa. No quiere aceptar responsabilidad ninguna, no es capaz ni de alquilarse un apartamento; a nosotros no nos estorba, pero ¿tú te crees que es normal, con su edad y dependiendo de los padres? (...) Lo de la película me lo ha contado, pero es muy difícil. (...) Sí, lo de la novia también, Malena, muy buena chica; pero eso no quiere decir que esté centrado... Bueno, de verdad, perdona que te haya puesto en esta situación, yo sé que eres su amigo.

\section{Sunlight in a Cafeteria, 1958}

¡Venga ya! Lo que pasa es que no tengo suerte ninguna con las tías. Hasta principios de año he estado con una rusa, de San Petersburgo, como el museo. La tía es traductora en el juzgado. La conozco en una fiesta, nos liamos. Todo bien. Pasamos juntos Noche Buena y Navidad. ¡Buen rollo! Hasta ejercemos de católicos y vamos a la misa del gallo. ¡Dos horas de ceremonia!, en ruso; no me cosqué de na', pero allí estaba yo, repeinado y oliendo a gloria bendita. Fiestón de Noche Vieja y el día de Año Nuevo los dos desparramaos en la cama. Por la noche, le hago un salmón en papillote rico de la muerte, nos liamos un rato y, a las cuatro de la mañana, yo qué sé por qué, la tía se despierta enfurruñada cagándose en to' lo que se menea -en ruso sí, pero te juro por Dios que se estaba cagando en to' lo que se menea-, y va y me echa de su casa. ¡Ahí lo llevas! Tenías que verme, en plena calle, con los pantalones a medio poner y cara de haberme caído de lo más alto de una higuera. ¡Y hasta hoy!

Luego, el día cuatro, estuve con Sara, ya sabes, el yogurcito que me tiro cuando encarta. Me la encontré por casualidad, a las siete de la mañana, en el SuperCor de San Julián. Yo iba a hacer jogging, ella volvía de marcha. La tía se mete en mi coche $\mathrm{y}$, como mis padres estaban en Madrid pasando las fiestas, 
C'est un peu salaud que je te raconte ça, mais bref...: Gaby n'avait pas de boulot, mais elle avait toujours son appart' à Mijas Costa, et elle avait toujours son petit gramme de coke et ses trois cents euros à flamber. Belle, élégante, sexy, avec deux portables, le sien et celui du boulot que soi-disant elle n'avait pas. Faut pas être devin...

Que les choses soient claires, je ne suis pas en train de la juger; pour survivre, on vend ce qu'on a vendre.

\section{Hotel Window, 1955}

Excuse-moi de t'embêter avec ça, mais je t'appelle parce que je me fais du mouron pour Francis (...) Son père biologique est mort il y a quinze jours. Franchement, excuse-moi, mais je t'en prie, essaie de me comprendre, je suis sa mère, et je m'en fais pour lui, c'est plus fort que moi. Son père a passé sa vie à faire la bringue à Torremolinos, entouré de crève-la-faim, de putains et de camés comme lui; et c'est comme ça qu'il a fini par crever comme un chien, entre deux conteneurs. J'ai peur que Francis ne finisse pareil. Il a presque la quarantaine, et il a quitté son travail. Il était bien, la télé, ça lui plaît, c'est un bon caméraman. Quelle vie l'attend? (...) Ça va faire comme avec Canal Nou, oui, il m'a raconté, mais ça n'est pas une excuse. Il ne veut jamais prendre de responsabilités, même prendre un appartement, c'est trop pour lui, ça n'est pas qu'il nous gêne, à la maison, mais tu trouves ça normal, toi, de dépendre encore de ses parents à son âge? (...) Il m'a dit pour le film, mais ça, ce n'est pas simple (...) Oui, il m'a dit aussi pour sa copine, Malena, une bonne petite; mais ce n'est pas pour ça qu'il a les pieds sur terre... Bon, excuse-moi encore de t'avoir embêté avec ça, je sais que tu es son ami.

\section{Sunlight in a Cafeteria, 1958}

Y'en a marre! Le truc, c'est que je n'ai vraiment pas de chance avec les filles. Jusqu'au début de l'année, j'étais avec une Russe, de Saint-Pétersbourg, comme le musée. La meuf est traductrice au tribunal. Je fais sa connaissance à une fête, on sort ensemble, tout bien. On passe le réveillon et le jour de Noël ensemble. Bon feeling! On la joue même bons cathos et on va à la messe de minuit. Deux heures de cérémonie! Et tout en russe, je n'ai pas capté un mot, mais j'étais là, tout beau, tout propre, et j'étais presqu'au paradis. Grosse fiesta pour la Saint Sylvestre, et le jour de l'An, on l'a passé sous la couette. Le soir, je lui fais un saumon en papillote à tomber par terre, on passe encore du bon temps et, à quatre heures du mat', va savoir pourquoi, la meuf se réveille en pétard contre tout et n'importe quoi, trop vénère, en russe, ah ça oui, mais trop vénère, je te jure, et tout d'un coup, elle me jette de chez elle. Et vas-y! T'aurais dû me voir, en pleine rue, à moitié à poil, avec la gueule du mec qui ne comprend pas ce qui lui arrive. Et à l'heure où je te parle, toujours pas de nouvelles.

Ensuite, le quatre, j'ai retrouvé Sara, tu sais, la lotita que je me tape à l'occasion. Je suis tombé dessus par hasard, à sept heures du mat', au SuperCor de San Julián. Je sortais courir et elle rentrait de soirée. Elle est montée dans 
el jogging lo hacemos en la cama. Pero espera, que la gracia no termina ahí, le preparo un arroz negro para almorzar y la nena llama a la hermana, Chiqui, estudiante de tercero de Derecho. Tomamos unas copas, “iJi, ji! ¡Ja, ja!", y terminamos montándonos un trío.

¡Vale!, muy morboso y todo lo que quieras, pero no me saca de nada. Así que, ¡yo qué sé!, si algún día dejo de atraer a las zumbás, lo mismo encuentro algo estable; pero, ¡vamos!, que de single estoy que me salgo.

\section{Early Sunday Morning, 1930}

Me considero una persona responsable y honesta. Desde que estudié en el instituto el esquema de Jakobson estoy fascinado por la comunicación. En principio, me interesaba desde un punto de vista intuitivo, pero en seguida me centré en los aspectos técnicos. Ahora, lo que me apasiona es su capacidad para influir en el curso de la historia. Goebbels, por ejemplo: "Una mentira repetida mil veces se convierte en verdad”. ¡Guaaaau!, un visionario, no me digan que no.

Nunca he servido a ningún partido. Mi único interés es hacer un buen trabajo y recibir un sueldo coherente con lo que produzco. Soy una persona leal, no obstante, he aprendido de mis maestros que no puedes fiarte de nadie, porque, si tienen mucho que ganar, incluso tus discípulos te acaban traicionando. Es la condición humana; por eso, mi lealtad está exclusivamente con la mano que me alimenta.

\section{Office in a Small City, 1953}

¡Hostia, Mike, no te estreses! Quedamos en que tú te encargabas del guion y de la dirección de actores, y yo de la producción y de la dirección cinematográfica, ¿no? Pues no me jodas y déjame trabajar; ya lo sabes, soy capaz de convencer a cualquiera de lo que sea. En cuanto tengas la nueva versión, me la pasas y yo me subo a Madrid y la muevo por allí. Por una vez, tenemos el santo de cara: gracias a la mujer de Tony he conseguido un contacto que va a abrirnos las puertas de A3 Media Cine.

\section{Self-Portrait, 1930}

¡Es que no nos sale nada bien! Primero nos dejan tirados los rusos; un millón que se fue volando, ¿y por qué? Nadie sabe nada, se quitaron de en medio y ya está. Luego, los de Marbella..., los de los coches de lujo. ¡Ya sé que quebraron!, pero los guiones de los anuncios se los entregamos; el trabajo estaba hecho, Francis, ijoder!, otro proyecto que nos comimos con papas. Y ahora estos cabrones nos ofrecen diez mil euros por el guion y hacen ellos la película. ¡Son A3 Media, cojones!, pueden permitirse pagarnos dignamente. Además, ¿qué pasa con la producción? Somos dos en esta empresa. ¿Qué quieres que te diga? No podemos aceptarlo. Es inviable. Diles que no y en cuanto lo hagas nos reunimos para planificar lo que sigue; pero, Francis, a partir de aquí me ocupo 
ma voiture, et vu que mes parents étaient partis à Madrid pour les fêtes, mon footing, on l'a fait au lit. Mais attends, encore plus fort, je lui prépare un riz à l'encre de seiche pour déjeuner, et la petite, elle appelle sa sœur, Chiqui, qui est en troisième année de Droit. On boit quelques verres, on déconne, et on finit par se faire un plan à trois.

Ok! C'est un truc de ouf, tout ce que tu voudras, mais c'est pas comme ça que je vais avancer. Alors, bon, j'sais pas, mais si j'arrête un jour d'attirer les meufs zarbi, peut-être que je vais me stabiliser; mais bon, je kiffe trop d'être célibataire.

\section{Early Sunday Morning, 1930}

Je considère que je suis quelqu'un d'honnête et de responsable. Depuis le jour où l'on m’a parlé de Jakobson, au lycée, je suis fasciné par la communication. En principe, cela m'intéressait d'un point de vue intuitif, mais je me suis tout de suite intéressé aux aspects techniques. Maintenant, ce qui me passionne, c'est sa capacité à infléchir le cours de l'histoire. Goebbels, par exemple: «un mensonge répété cent fois devient la vérité» Waouh! Un visionnaire, ne me dites pas le contraire.

Je n'ai jamais servi les intérêts d'aucun parti. Mon seul intérêt, c'est de faire du bon travail et de recevoir en retour un salaire cohérent. Je suis quelqu'un de loyal, mais j'ai malgré tout appris de mes maîtres qu'on ne peut faire confiance à personne, parce que, s'ils ont beaucoup à y gagner, même tes disciples finiront par te trahir. C'est la condition humaine; c'est pourquoi je ne suis loyal qu'envers la main qui me nourrit.

\section{Office in a Small City, 1953}

Putain, Mike, arrête de stresser! On avait dit que toi, tu t'occupais du scénario et de la direction des acteurs, et moi, de la production et de la direction cinématographique, hein? Bon, alors, fais pas chier et laisse-moi bosser; tu sais bien que je suis capable de convaincre n'importe qui de n'importe quoi. Dès que t'as fini ta dernière version, tu me la refiles et je monte à Madrid et je mets tout en branle. Pour une fois, les dieux sont avec nous: grâce à la femme de Tony, j'ai un contact qui va nous ouvrir les portes de A3 Media Cine.

\section{Self-Portrait, 1930}

C'est que tout part toujours en couille! D'abord, il y eu les Russes, qui nous ont plantés; un million envolé, et pourquoi ? Personne n'en sait rien, ils ont quitté le projet, un point c'est tout. Puis les types de Marbella..., ceux des voitures de luxe. Je sais bien qu'ils ont fait faillite! Mais on leur avait remis les scénarios des pubs; le boulot était fait, putain, Francis! Un autre projet pour lequel on peut aller se brosser. Et maintenant, ces enfoirés nous offrent dix mille euros pour le scénario et c'est eux qui font le film. C'est quand même A3 Media, merde! ils ont les moyens de nous payer décemment. En plus, qu'est-ce qu'il en est de la production? On est deux dans cette entreprise. Qu'est-ce que tu veux que je te dise? On ne peut pas accepter. Ce n'est pas viable. Tu leur dis non, et quand c'est 
contigo de la producción. Yo no estoy diciendo que sea culpa tuya, quítatelo de la cabeza, lo que estoy diciendo es que, de las gestiones que llevamos, en dos nos han dejado tirados y en la tercera nos han hecho una oferta infame, y que en ninguna de las tres he estado yo presente. ¡Eso se acabó! Conozco a los de A3 Media por los whatsapps que me has reenviado, a los demás ni eso, ¿tú te crees que es normal? Me jode volver a la gestión, pero es que no nos queda otra. Y no pienso que lo estés haciendo mal, créeme, pero estoy convencido de que la única forma de sacar adelante esta película es que los dos tiremos de la producción.

\section{Conference at Night, 1949}

Con quince años, coincidiendo con la época en que me fui a vivir con mis abuelos, comencé a frecuentar la agrupación de Benalmádena. En cuanto cumplí los dieciocho, me afilié. A los veintiuno, les devolví el carné con una nota en la que los animaba a que se lo metiesen donde les cupiese. ¡Ni te imaginas lo que allí había! Era un puto nido de víboras, sobre todo las juventudes. En una elección de representantes, Montserrat y el novio manipularon las listas para que los que nos oponíamos a ella no pudiésemos votar. Ese fue su primer paso, y mírala donde está ahora. Al exnovio me lo encontré hace poco, trabaja en una gasolinera de Estepona. El cabrón me pidió perdón. Tampoco está ya en el partido.

Nunca me he arrepentido de haber entregado el carné, y eso que me costó una bronca con mi abuelo. La integridad, siempre por delante. Desde entonces, como Herrera, voto al Partido Comunista del Pueblo Andaluz, "son enternecedores".

\section{Excursion into Philosophy, 1959}

Mira, sabes que Francis y yo somos amigos, pero la dirección no es buena. Esas luces tan contrastadas resaltan las partes dramáticas y ahogan la comicidad, y lo mismo pasa con el ritmo, os sobran veinte minutos por lo menos. El espacio está mal diseñado; la disposición escénica es patética. Lo único que se salva es tu parte, eres una actriz excelente. (...) ¿Por qué no me llamasteis? Da igual, buscad ayuda, que alguien os asesore, pero arregladlo. (...) Da igual, buscad ayuda, que alguien os asesore, pero arregladlo. (...)

No te entiendo. Tenías muchas esperanzas en este proyecto. ¿Qué cojones ha pasado? (...) Pero, ¿qué...? ¡Joder! Terminasteis bien, ahora sois amigos. Durante estos meses habéis luchado contra/ (...) ¡Que "tienes que pensar en tu hijo”! ¡No me jodas! ¿Qué significa eso? ¿De qué es capaz Francis, Malena? ¿De qué es capaz? ¿Qué es lo que me estás diciendo? No, no, ahora no escondas la mano, si pasó algo chungo entre vosotros dímelo. 
fait, on se retrouve pour planifier la suite; mais Francis, à partir de maintenant, on s'occupe tous les deux de la production. Je ne dis pas que c'est ta faute, ôte-toi ça de l'esprit, ce que je dis, c'est que des trois projets qu'on a, on nous a laissés tomber pour deux d'entre eux et qu'on nous a fait une offre insultante pour le troisième, et que dans ces trois cas, je n'ai jamais été associé aux démarches. Ça, c'est fini! Je connais les gens de A3 Media, à travers les WhatsApps que tu m'as fait suivre, et les autres, je ne sais même pas qui c'est, tu trouves ça normal? Ça me gonfle de reprendre la gestion, mais on n'a pas le choix. Je ne crois pas que tu fasses les choses de travers, crois-moi, mais je suis convaincu que la seule façon de sortir ce film, c'est qu'on s'occupe tous les deux de la prod'.

\section{Conference at Night, 1949}

À quinze ans, à l'époque où je suis parti vivre avec mes grands-parents, j'ai commencé à fréquenter le groupe de Benalmádena. Quand j'en ai eu dixhuit, j'y ai pris ma carte. À vingt et un ans, je l'ai rendue avec un petit mot leur recommandant de se la mettre là où je pense. Tu n'as pas idée de ce qui s'y passait! C'était un foutu panier de crabes, surtout dans ses branches «jeunesse». Au cours d'élections de représentants, Montserrat et son fiancé ont manipulé les listes pour empêcher de voter ceux qui, comme moi, s'opposaient à eux. Ça a été sa première manœuvre, et regarde où ça l'a conduite aujourd'hui. Je suis tombé sur son ex-fiancé, il y a peu, il travaille dans une station-service, à Estepona. Cet enfoiré m’a demandé pardon. Lui aussi a quitté le parti.

Je n'ai jamais regretté d'avoir rendu ma carte, même si je me suis pris un sacré savon de la part du grand-père. L'intégrité avant toute chose. Depuis, comme Herrera, je vote pour le Parti Communiste du Peuple Andalou, «je les trouve touchants».

\section{Excursion into Philosophy, 1959}

Écoute, tu sais que Francis est mon ami, mais pour la mise en scène, il y a des trucs à changer. Ces lumières trop contrastées font ressortir le dramatisme, mais étouffent la dimension comique, et même chose au niveau du rythme, vous avez au moins vingt minutes de trop. L'espace est mal dessiné; la disposition scénique est pathétique. La seule partie qui tire son épingle du jeu, c'est ta partie, tu es une actrice excellente (...) Pourquoi est-ce que vous n'avez pas fait appel à moi ? Peu importe, demandez de l'aide, faites-vous assister par quelqu'un, mais remédiez à cela. (...).

Je ne te comprends pas. Tu avais placé beaucoup d'espoir dans ce projet. Putain, mais qu'est-ce qui s'est passé? (...) Qu'est-ce que vous avez foutu? Vous êtes restés bons amis, pas vrai? Pendant tous ces mois, vous avez lutté contre (...) Tu dois penser à ton fils! Sans déconner! Qu'est-ce que ça veut dire? De quoi est-ce que Francis est capable, Malena? De quoi il est capable? Qu'est-ce que tu me racontes? Non, non, ce n'est pas la peine de faire semblant, s'il s'est passé quelque chose entre vous, dis-le-moi. 


\section{Two on the Aisle, 1927}

En cinco años seré Director General de Comunicación de una empresa importante y significativa en el panorama nacional. ¿Por qué no esta? No me veo haciendo carrera política, pero sí ayudando al líder adecuado a alcanzar la presidencia.

Me interesa vuestro programa. Acabo de dejar Marbella Televisión porque la "derechita cobarde" se la está cargando. Se puede hacer mejor, ¿estáis dispuestos a intentarlo?

\section{Sunday, 1926}

¿Qué está pasando, Francis? Y no me vengas con historias. Quiero que me digas la verdad... ¡Pero, tío! ¿Por qué lloras? ¿Tan mal está la cosa? ¡Venga hombre, que no es para tanto! Si los de A3 Media han querido engañarnos, peor para ellos; nos buscamos la vida y hacemos nosotros la película. Tenemos equipo, solo es cuestión de encontrar el dinero. Pero no me vengas con rollos raros. ¿Qué es, por Malena? ¿Por la obra? Pasa del tema. Os dije que os ayudaría, tenías que haberme llamado. También podéis hablar con directoras como Mercedes León o Marina Devesa. ¡Deja de llorar, hombre! Todo tiene arreglo. Y si la obra se te ha enconado, ijoder!, pasa página; cédele el montaje a Malena y se acabó. ¡Será por proyectos!

\section{Hotel Room, 1931}

Por ahora no puedo seguir con la obra. (...) Tú eres su amigo. (...) ¿Sus padres? No, sus padres son estupendos, el cabrón es él. Ellos solo tratan de ayudarle, como todos los demás, pero ya ves que no se nos da muy bien. (...) Se mete de todo. (...) ¿Y qué esperabas que hiciese? Miguel, es un jonky. (...) Te ha dicho lo que querías oír, como a mí, como a todos. Desengáñate, Francis no tiene amigos.

\section{New York Movie, 1939}

¡Hola! ¿Dónde estás? (...) ¿A qué hora vuelves al rodaje? (...) Toro... No, no me suena. (...) ¡Mira!, tengo que hablar contigo. (...) Sí, sobre la película. Dime dónde vais a estar en treinta minutos y me acerco. (...) No te preocupes por eso, conozco a Kike Maíllo desde hace un porrón de años. (...) ¡Vale!, pero, aunque sea en exteriores, alguien sabrá dónde vais a estar. Pregúntale al ayudante de dirección. (...) ¡Claro!, no es tan urgente. Tranqui, te llamo en un par de días.

\section{People in the Sun, 1960}

Komo stas, loko?

$\mathrm{M}$ voy a Acapulco una temporada. Tengo un colega ke se fue pallá pa ncontrarse a si mismo. Entre l yoga y la meditación se saca una pasta gansa con los videos d aventura pa los niños ricos. Stá ampliando 1 negocio y kiere ke 1 ayude. 


\section{Two on the Aisle, 1927}

Dans cinq ans, je serai Directeur Général de la Communication dans une grosse entreprise, parmi les plus en vue au niveau national. Alors, pourquoi pas celle-ci? Je ne me vois pas faire une carrière politique, mais plutôt aider le leader adéquat à gagner la présidence.

Votre programme m'intéresse. Je viens de quitter Marbella Televisión parce que la «droite frileuse» est en train de les couler. On peut faire les choses mieux que ça, vous êtes partants?

\section{Sunday, 1926}

Qu'est-ce qui se passe, Francis? Et ne me raconte pas de craques. Je veux que tu me dises la vérité... Mais pourquoi tu pleures, mon vieux? Les affaires vont si mal que ça? Allez, mon vieux, c'est pas la fin du monde! Si chez A3 Media, ils ont voulu nous entuber, tant pis pour eux; on va se débrouiller et monter notre film tout seuls. On a une équipe, il n'y a plus qu'à trouver l'argent. Mais arrête tes plans foireux. C'est quoi le problème, c'est à cause de Malena? C'est la pièce? Oublie. Je vous ai dit que je vous aiderais, t'aurais dû m'appeler. Vous pouvez aussi parler avec des metteurs en scène comme Mercedes León ou Marina Devesa. Arrête de pleurer, mon vieux! Il y a toujours une solution. Si t'en peux plus de cette pièce, passe à autre chose, putain, cède le tout à Malena, et on n'en parle plus. Il y en aura d'autres!

\section{Hotel Room, 1931}

Pour le moment, je ne peux pas continuer la pièce. (...) Tu es son ami. (...) Ses parents? Non, ses parents sont super, c'est lui qui est con. Eux, ils essaient juste de l'aider, comme tout le monde, mais ça n'est pas vraiment concluant, tu vois. (...) Il prend toute sorte de saloperies. (...) Et qu'est-ce que tu voulais qu'il fasse, Miguel? C'est un junkie. (...) Il t'a dit ce que tu voulais entendre, comme pour moi et pour tous les autres. Ouvre les yeux, Francis n'a pas d'amis.

\section{New York Movie, 1939}

Salut! T'es où? (...) À quelle heure est-ce que tu reviens sur le tournage? (...) Toro... Non, ça ne me dit rien (...) Écoute, il faut qu'on parle! (...) Oui, au sujet $\mathrm{du}$ film. Dis-moi où vous serez dans une demi-heure et je vous retrouve (...) $\mathrm{Ne}$ t'inquiète pas pour ça, avec Kike Maillo, on se connaît depuis des lustres. (...) D'accord, mais même si vous tournez des extérieurs, il y a bien quelqu'un qui doit savoir où vous serez! Demande à l'assistant réalisateur. (...) Bien sûr, il n’y a pas d'urgence! Te bile pas, je te rappelle dans deux jours.

\section{People in the Sun, 1960}

Sava, poteau?

J'V à Acapulco passer qq mois. J'ai un poto K parti laba pour se r'trouver. Entre le yoga et la médit' Y s'fait grave des thunes en postant des vidéos d'aventures pour les gosses de riches. Le business se développe et Y veut Ke jl'aide. 
Necesito un cambio d aires. No puedo pensar ahora $n$ la peli, a la vuelta retomamos.

Hasta luego!!!!!!! :)

\section{Rooms by the Sea, 1951}

Mírame a los ojos y dime que es mentira, que no le pusiste tu nombre a mi guion y se lo vendiste a A3 Media como si fuese tuyo. (...) ¿Cómo pudiste hacerlo, soy tu amigo? (...) ¿No has visto El Bar? Es mi puto guion, Francis. Es mi puto guion. Cuando la estaba viendo no daba crédito: las mismas ideas, la misma estructura de la acción, la misma reflexión sobre la condición humana. ¡Joder! Si hasta ficharon a Blanca Suárez. No es justo. La película es una mierda, pero está levantada a partir de mi guión. (...) Eres un hijo de puta, me has apuñalado por la espalda. (...) ¡Déjate de gilipolleces y admítelo de una vez! Sé que tienes problemas con las drogas. Al final, todo el mundo larga. Además, es que eres muy tonto, lo tengo registrado desde el primer borrador. Voy a denunciarte. (...) Eso ya lo veremos. Dónde me gasto mi dinero lo decido yo y, como que me llamo Palacios, no voy a parar hasta que todo salga a la luz y pagues por lo que has hecho.

\section{Summer Interior, 1909}

Yo lo que digo es que el sistema nos oprime porque nos dejamos oprimir. He conocido poca gente íntegra en mi vida, mi abuelo y tú entre ellos, y te digo que, si todo el mundo fuese así, la realidad sería distinta. Pero, míralos: aislados, aborregados, espiando al vecino por si fuese un yihadista, un depredador sexual o un colgao. Así, ¿quién va a construir una ciudadanía democrática en este país? Somos la presa ideal para el fascismo. Ser libres nos da tanto miedo que, en cuanto un nuevo profeta aparece, nos aferramos a él sin cuestionar lo que dice. Es el sino de un pueblo ignorante: cambiar un dictador por otro.

Tenemos que seguir luchando, cada uno desde la trinchera en la que está. Yo no pienso rendirme, yo voy a montar tu obra con Malena y voy a encontrar el dinero para que hagamos la película. Esa es mi trinchera. Desde ahí, fiel a mis ideales, voy a combatir con todas mis fuerzas la opresión. Por mi abuelo, por mí mismo. Y si para eso tengo que enfrentarme a un sistema autoritario e inhumano, lo haré. Y si eso supone dejarme el alma en la batalla, te garantizo que también lo haré.

\section{Blue Night, 1914}

Nada. (...) Eso mismo. (...) Tan fácil como comprobar que ha puesto su nombre en mi guion, hace años que lo tengo registrado. (...) Ya, pero la decisión es mía, y es la que es: lo dejo. (...) Ganar no va a hacer que me sienta mejor. Creía que era mi amigo. Me fiaba de él y me ha traicionado. Hasta me hizo cómplice 
G besoin d'changer d'R. G pas la tête O film, on en r'parle ASAP, dak?

Slt!!!!! :)

\section{Rooms by the sea, 1951}

Regarde-moi dans les yeux, et dis-moi que ce n'est pas vrai, que tu n'as pas mis ton nom en bas de mon scénario et que tu ne l'as pas vendu à A3 Media comme s'il était de toi? (...) Comment est-ce que tu as pu me faire ça? Je suis ton ami. (...) Tu as vu El Bar? Putain, mais c'est mon scénar. Je n’en croyais pas mes yeux; mêmes idées, même structure de l'action, même réflexion sur la condition humaine. Ils ont même pris Blanca Suárez, putain, j’y crois pas. C’est pas juste. Le film est une merde, mais il a été fait à partir de mon scénario. (...) T'es le pire des enfoirés, tu m'as poignardé dans le dos. (...) Arrête tes conneries et admets-le une fois pour toutes! Je sais que t'as un problème avec la drogue. Tu sais, les gens parlent. En plus, t'es vraiment pas malin, j'ai déposé le projet, dès ma première version. Je vais porter plainte. (...) Ça, on verra après. C'est moi qui décide de quelle façon je veux dépenser mon argent et, aussi vrai que je m'appelle Palacios, je ne m'arrêterai pas jusqu'à ce que toute la lumière soit faite et que tu paies pour ce que tu as fait.

\section{Summer Interior, 1909}

Moi, ce que je dis, c'est que si on est opprimés par le système, c'est parce qu'on se laisse opprimer. J'ai connu assez peu de gens intègres, dans ma vie, mon grand-père et toi en faites partie. Je te dis que si tout le monde était comme vous, la réalité serait bien différente. Mais regarde-les: isolés, des vrais moutons, à épier leur voisin au cas où ce serait un djihadiste, un prédateur sexuel ou un camé. Du coup, comment veux-tu qu'on arrive à construire une citoyenneté démocratique dans ce pays? On est la proie idéale pour le fascisme. On a si peur d'être libres que, dès qu'un nouveau prophète fait son apparition, on s'y accroche sans remettre en question ce qu'il raconte. C'est le destin d'un peuple ignorant: passer d'un dictateur à un autre.

On doit poursuivre la lutte, chacun depuis sa tranchée. Pour ma part, je ne pense pas baisser les bras, je vais monter ta pièce avec Malena et je vais trouver l'argent pour qu'on puisse faire le film. Voilà ma tranchée. Fidèle à mes idéaux, j’y combattrai l'oppression, de toutes mes forces. Pour mon grand-père, pour moimême. Si pour cela je dois affronter un système autoritaire et inhumain, je le ferai. Et si ça implique de mourir au champ d'honneur, je te promets que je le ferai.

\section{Blue Night, 1914}

C’est ça. (...) Exactement. (...) C'est pas bien difficile de vérifier qu'il a mis son nom sur mon scénario, je l'ai déposé il y a des années. (...) Oui, mais la décision m'appartient, et c'est comme ça: je laisse tomber. [...] Je ne vais pas me sentir mieux si je gagne. Je croyais que c'était mon ami. Je lui faisais confiance et il m'a trahi. Il m'a même rendu complice du mensonge fait à Malena et à sa mère. C'est un enfoiré de manipulateur, il savait que je ne le laisserais pas tomber et que, du coup, je ne vendrais pas le scénario à A3 Media Cine. C'est pas un petit 
de su engaño a Malena y a su madre. Es un puto marionetista, sabía que no lo dejaría tirado y que, por eso mismo, jamás le vendería el guión a A3 Media Cine. ¿Es o no es una jugada maestra? Utilizó mi integridad para timarme. Y, por si no picaba, lo que dijo que me ofrecían es una miseria. Jackpot, baby!

¡Perdona! ¿Puedes encender la luz de sala? Me gustaría ver al público... Gracias. Soy Miguel Palacios, el autor de Hopper's Blue Night. Escribí esta obra porque necesitaba contar lo que me pasó con el guion de La cloaca, ese que mi socio y amigo Francis B. vendió a mis espaldas fingiendo que era suyo. Desde el principio, todo fue una gran mentira; o tal vez no, quizá la mentira surgió cuando Francis se dio cuenta de la enorme cantidad de energía que había que poner para sacar adelante el proyecto, o cuando volvió a consumir... Yo qué sé. ¿No se metía ya antes? ¡Por supuesto que sí! El fallo fue mío, estaba tan entusiasmado con hacer la película, que no leí los signos, y eso que algunos eran fluorescentes, parpadeaban y llevaban encima una sirena pitando. ¡Seré idiota! No lo vi venir. Si no llega a ser por Malena no me hubiese enterado de nada. Por cierto, Malena, en realidad, no se llama Malena.

Otra cosa de la que estoy convencido es que Francis iba a seguir exprimiéndome, por eso no se quitó de en medio hasta lo de la llorera. Esa escena tuvo lugar en un kebab del Plaza Mayor, la recuerdo como si fuese ayer. Pensó que lo había pillado, por eso la bulla con que se largó a México...; aunque ya tampoco me creo que se fuese a ningún sitio. En el fondo, la situación le ponía. Seguro que pensaba que lo tenía todo controlado, que podía manejarme a su antojo; al fin y al cabo, yo era el protagonista de su historia. ¡Qué ironía!, ¿no les parece? El autor convertido en marioneta. ¿Dónde deja eso a mis personajes? ¿Y a mí, a mí dónde me deja?

No puedo continuar evitando los signos: soy el personaje de una ficción urdida por una mente intoxicada, el personaje de una obra en la que se declina la mentira, el personaje de una vida en el teatro de la realidad... Si solo fuese eso, si cada ser humano solo llevase consigo un par de personajes, qué fácil sería desvelar los entresijos de la existencia.

El impacto de la traición ha ampliado mi percepción de cuanto me rodea. El mundo es un laberinto inabarcable que gira frenéticamente en todas direcciones. ¿A qué voy a agarrarme para no salir despedido de él? ¿Cómo voy a evitar que me engulla la locura? ¿Cómo interpretar al ser humano desde aquí? ¿Cómo, si veo los personajes de los demás tan nítidos como los míos propios? ¿Y, entonces, qué, escucho a quien me hable como a la lluvia? ¿Tiro la toalla? ¿O asumo que desde el momento en que nacemos estamos sometidos a una formidable mentira, a un absurdo y cósmico guiñol, y continúo caminando con mis máscaras, aguantando sobre los hombros el insoportable peso de esa verdad?

En fin, ahora ya saben lo que ocurrió. Todo cierto... ¿Lo es? Estamos en el teatro, en una obra cuyo tema central es la mentira. ¿Quieren más? Yo no soy Miguel Palacios, me llamo (el actor dice su nombre y apellidos), soy actor y hoy me ha tocado interpretar a Miguel Palacios, el autor, y a Miguel Palacios, su personaje; ambos, a su vez, personajes de Hopper's Blue Night, de Miguel 
chef-d'œuvre de la manip', ça? Il s'est servi de mon intégrité pour me planter. Et au cas où je ne mordrais pas à l'hameçon, il m'a dit qu'ils nous en offraient une misère. Jackpot, baby!

Excuse-moi, tu peux éclairer la salle? Je voudrais voir le public... merci. Je m'appelle Miguel Palacios, je suis l'auteur de Hopper's Blue Night. J'ai écrit cette pièce parce que j'avais besoin de raconter ce qui m'est arrivé avec le scénario de La cloaca, celui que mon associé et ami, Francis B., a vendu dans mon dos, comme s'il était de lui. Dès le début, tout a été un grand mensonge; ou peut-être pas, peut-être que le mensonge est arrivé le jour où Francis s'est rendu compte de l'énorme quantité d'énergie requise pour mener à bien ce projet, ou le jour où il s'est remis à consommer... Allez savoir. Il ne consommait pas déjà, avant? Bien sûr que si! C'est ma faute, j'étais si enthousiaste à l'idée de faire le film, que je n'ai pas vu les signes, et dieu sait s'ils étaient fluorescents et clignotants, des vrais girophares. Il faut être stupide! Je n'ai rien vu venir. S’il n'y avait pas eu Malena, je n'aurais jamais rien su. Au fait, Malena, en réalité, ne s'appelle pas Malena.

S'il y a bien autre chose dont je suis convaincu, c'est que Francis allait profiter de moi, c'est pour cela qu'il ne s'est pas retiré jusqu'au jour où il s'est mis à chialer. Cette scène s'est déroulée dans un kebab du centre commercial Plaza Mayor, je le revois comme si c'était hier. Il s'est dit que je l'avais percé à jour, d'où les craques sur son voyage au Mexique..., même si, maintenant, je doute qu'il soit parti où que ce soit. Au fond, la situation l'excitait. Je suis sûr qu'il se disait qu'il avait tout sous contrôle, qu'il pouvait me manipuler à sa guise; après tout, j'étais le protagoniste de son histoire. Quelle ironie! Vous ne trouvez pas? L'auteur devenu une marionnette. Et qu'est-ce que ça fait de mes personnages? Et qu'est-ce que ça fait de moi?

Je ne peux pas continuer à faire comme si je ne voyais pas les signes: je suis le personnage d'une fiction pensée par un esprit intoxiqué, le personnage d'une pièce où se décline le mensonge, le personnage d'une vie, dans le théâtre de la réalité... Si ça n'allait pas plus loin, si chaque être humain n'emmenait avec lui que deux personnages, comme il serait facile de démêler les entrelacs de l'existence.

L'impact de sa trahison a aiguisé ma perception de tout ce qui m'entoure. Le monde est un labyrinthe dont on ne peut faire le tour, et qui tourne dans tous les sens, de façon frénétique. À quoi est-ce que je vais pouvoir me raccrocher pour éviter d'en être éjecté? Comment éviter de sombrer dans la folie? Comment interpréter l'être humain, de là où je me trouve? Comment, si je perçois les personnages des autres aussi clairement que les miens? Et alors, quoi, j'écoute ceux qui me parlent comme j'entends la pluie tomber? Je jette l'éponge? Ou bien j'assume que dès notre naissance, nous sommes victimes d'un formidable mensonge et sommes les pantins d'une représentation cosmique et absurde de Guignol, et je continue d'avancer masqué, portant sur mes épaules le fardeau insupportable de cette vérité?

Bref, vous savez désormais tout ce qui est arrivé. Tout est vrai... Vraiment? Nous sommes au théâtre, dans une pièce dont le thème central est le mensonge. Ça ne vous suffit pas? Moi, je ne suis pas Miguel Palacios, je m'appelle (l'acteur 
Palacios. Partiendo de esa realidad, ¿qué verdad puede haber en cualquier cosa que cualquiera de mis yoes diga desde aquí?

Disfruten del final del espectáculo.

\section{Automat, 1927}

Mi abuelo es la persona que más ha influido en mi vida. Era un gran tipo. El 18 de julio le pilló en Málaga, donde vivía su familia. Allí, en 1937, con sus padres y hermanos, participó en el recibimiento triunfal de los camisas negras italianos a las órdenes del Bando Nacional. Tenía quince años y no dudó ni un instante en unirse a las tropas franquistas para tomar parte activa en la cruzada contra el comunismo, cansado de que sus huestes quemasen iglesias y enterrasen a miles de buenos católicos en las cunetas después de fusilarlos.

En marzo del treinta y siete participó en la batalla de Madrid y, un año más tarde, en la Sierra de Pàndols, frente del Ebro. Finalmente, en enero del treinta y nueve contribuyó a liberar Barcelona.

Al término de la guerra, mi abuelo continuó su actividad política en el Frente de Juventudes, y después en Falange Española, siendo elegido como procurador de las Cortes en 1959. Durante la Transición, se afilió a Alianza Popular y, en 1989, al PP, del que continuó siendo miembro hasta su fallecimiento.

Era un tipo íntegro, serio, que no se andaba con chiquitas, pero honesto y justo a más no poder. A mí siempre me trató bien: "el jefecito", me llamaba, porque, decía, era el que tenía más carácter de todos sus nietos. En la época en que las cosas con mis padres comenzaron a torcerse, él y mi abuela fueron los únicos que me tendieron la mano.

Le echo de menos, sí. También a ella. No hay un día que pase en el que no lo recuerde, por eso digo que es la persona de mi familia que más ha influido en mi vida; en todo lo que hago trato de parecerme a él.

\section{Two Comedians, 1966}

Soy capaz de convencer a cualquiera.

¿Tenéis una idea? Dejadme ayudaros, yo haré que el país entero la abrace. ¿Sabéis qué os digo? Escuchad con atención lo que os digo.

"Nadie en el tercio sabía quién era aquel legionario..." 
donne son prénom et son nom), je suis un acteur, et aujourd'hui, il me revient d'interpréter Miguel Palacios, l'auteur, et Miguel Palacios, son personnage; tous deux, à leur tour, personnages de Hopper's Blue Night, de Miguel Palacios. Partant de là, quelle vérité peut sortir de la bouche de chacun de ces Moi, ici et maintenant?

Je vous laisse profiter de la fin du spectacle.

\section{Automat, 1927}

Mon grand-père est la personne qui a le plus influencé ma vie. C'était vraiment quelqu'un. Le 18 juillet le surprit à Malaga, où il vivait avec sa famille. C'est là qu'il accueillit triomphalement, en 1937, en compagnie de ses frères et sœurs et de ses parents, les Chemises Noires italiennes aux ordres des Nationalistes. Il avait quinze ans, et n'hésita pas un instant à rejoindre les troupes franquistes pour participer activement à la croisade contre le communisme, las de voir ses troupes brûler les églises et enterrer des milliers de bons catholiques au bord du chemin, après les avoir fusillés.

En mars 1937, il participa à la bataille de Madrid et, un an plus tard, à celle de la Sierra de Pàndols, sur le front de l'Èbre. Pour finir, il contribua à la libération de Barcelone, en janvier 1939.

À la fin de la guerre, mon grand-père poursuivit son engagement politique au Frente de Juventudes, puis à la Falange Española, étant élu député régional en 1959. Durant la Transition, il a rejoint la Alianza Popular puis, en 1989, le Partido Popular, dont il a été membre jusqu'à sa mort.

C'était un homme intègre, droit, qui ne s'embarrassait pas de fioritures, le plus honnête et le plus juste des hommes. Il a toujours été gentil avec moi: il m'appelait son "petit chef», parce que, disait-il, c'est moi qui avais le plus de tempérament de tous ses petits-enfants. À l'époque où les choses commencèrent à se compliquer avec mes parents, il n'y eut que lui et ma grand-mère pour me tendre la main.

Il me manque, ça oui. Et elle aussi. Il ne se passe pas un jour sans que je pense à lui, c'est pour cela que je dis que c'est la personne qui a le plus influencé ma vie; j'essaie de lui ressembler en tout.

\section{Two Comedians, 1966}

Je suis capable de convaincre n'importe qui.

Vous avez une idée? Laissez-moi vous aider, et je ferai en sorte que le pays tout entier $\mathrm{y}$ adhère.

Vous savez ce que je vous dis? Faites bien attention à ce que je vais vous dire. «Personne dans la troupe ne savait qui était ce légionnaire ${ }^{5} . . . »$

Portlligat, octobre 2029

5 Il s'agit du début de la chanson, citée dans le tableau 2, "El novio de la muerte", qu'entonnent pendant leurs meetings les membres du parti politique VOX. 